\title{
Responses in human $\mathrm{A}$ and $\mathrm{C}$ fibres to repeated electrical intradermal stimulation ${ }^{1}$
}

\author{
H. ERIK TOREBJÖRK AND ROLF G. HALLIN \\ From the Department of Clinical Neurophysiology, University Hospital, Uppsala, Sweden
}

SYNOPSIS The responses of $\mathrm{A}$ and $\mathrm{C}$ fibres to electrical intradermal stimulation were recorded with microelectrodes inserted percutaneously into intact human skin nerves. Unitary discharges deriving from A fibres were often encountered and sometimes even single $\mathrm{C}$ unit deflections were identified. When several $\mathrm{C}$ fibres responded to the stimulation, a compact time presentation of the filtered and dot-converted spikes improved the discrimination of individual spikes time-locked to the stimulation, so that unitary $\mathrm{C}$ elements could often be identified in the treated records even if the signal-to-noise ratio of the original signals was low. Increases in latency or blockings were traced in both $\mathrm{A}$ and $\mathrm{C}$ unit responses to repeated excitation, but the influence of repeated activation was more pronounced in thin nerve fibres even at low stimulation frequencies. The decreased excitability of thin nerve endings on repetitive stimulation suggests that not only central factors but also excitation failure in peripheral thin nerve fibres might be responsible for the decrease in pain perception experienced during local intense electrical intradermal stimulation at high frequencies.

Macroelectrodes placed in the vicinity of a nerve trunk are used in clinical neurography to record electrically evoked compound potentials deriving from responses in large and small myelinated fibres (cf. for instance, Buchthal and Rosenfalck, 1966). As shown by Hallin and Torebjörk (1970a; 1973) microelectrode recordings from intact human nerve fascicles permit analysis of activity not only in myelinated but also in unmyelinated fibres in responses to electric skin shocks. In these investigations computer records of multifibre activity were analysed which did not yield detailed information on the influence of the stimulation on unitary elements contributing to the responses.

Since electrical stimulation of the skin is an easy way to induce neural activity in peripheral nerves and can be used routinely in clinical neurography, it seemed to be of interest to study the influence of repetitive electric excitation on human cutaneous $\mathrm{A}$ and $\mathrm{C}$ fibres as a basis to future pathophysiological and clinical diagnostic studies. In this study a display system was used which improved the discrimination of individual

1 Supported by the Swedish Medical Research Council, Grant no. B72-14X-2881-03A and AB Förenade Liv, Stockholm, Sweden. deflections from thin fibres even when many units responded to the stimulation and the signal-to-noise ratio was low. In particular, C components which were difficult to identify in the original neurogram often became discernible so that characteristic features of single elements could be studied in responses to repeated electrical stimulation.

\section{METHODS}

SUBJECTS The experiments were made on six healthy male adults aged 20 to 30 years. None of them had signs or symptoms of disease of any kind. No complications or enduring local symptoms were noted during this series of experiments.

RECORDING ELECTRODES Lacquer insulated tungsten microelectrodes were used. They had a diameter of $0.2 \mathrm{~mm}$ with a free tip less than $80 \mu \mathrm{m}$ long and a tip diameter less than $5 \mu \mathrm{m}$. The impedance tested after the experiments at $1 \mathrm{kHz}$ ranged from $30-150 \mathrm{k} \Omega$.

GENERAL PROCEDURE Details about the recording of impulse activity from intact human nerve fascicles were described in earlier reports (Vallbo and Hagbarth, 1968; Hagbarth et al., 1970). The general experimental situation was similar to that previously 

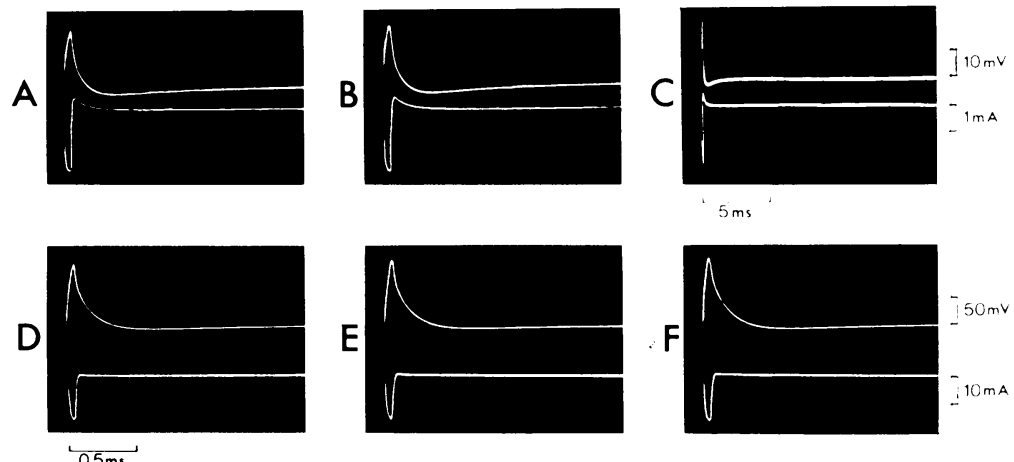

FIG. 1. DC-recordings of stimulus artefact (upper traces) and stimulus current (lower traces) measured at different stimulation frequencies. Stimulus artefact visualized as 'unipolar' recording with a needle electrode inserted into the skin between the stimulating needles. Stimulus current measured between the stimulating electrodes. Stimulus duration $0.05 \mathrm{~ms}$ in all traces. Ten sweeps superimposed in each record. $\mathrm{A}-\mathrm{C}$ and $\mathrm{D}-\mathrm{F}$ derive from two different experiments. Stimulation frequency $1 / \mathrm{s}$ in $\mathrm{A}$ and $100 / \mathrm{s}$ in $\mathrm{B}$ and C. No changes in stimulus artefact or stimulus current were observed with change in stimulation frequency. In D painful stimuli were delivered at $1 / \mathrm{s}$. On increasing the frequency to $10 / \mathrm{s}, \mathrm{E}$, the pain was initially severe, but on maintained stimulation at that frequency, F, the experience of pain gradually. decreased. Despite the changes in perception, the stimulus artefact and current remained constant. Time calibration in D refers to all records except $\mathrm{C}$.

described by Hallin and Torebjörk (1973). The recording electrode was inserted manually into the nerve and when an intraneural recording site was found the nerve response to electric skin stimuli was checked to discover $\mathrm{C}$ deflections. If only $\mathrm{A}$ fibre activity was recorded, minute movements of the intraneural electrode tip sometimes brought $\mathrm{C}$ components 'into focus'.

The findings presented derive from 15 experiments (14 recordings from the radial nerve at the wrist and one recording from the saphenous nerve below the knee), where we could identify $A$ and $C$ fibre impulses with the general characteristics described previously (Hallin and Torebjörk, 1973). Sometimes the discharges appeared so distinctly in the original neurogram that single $C$ unit responses could be identified according to the characteristics described by Torebjörk and Hallin (1970, 1974).

STIMULATION PROCEDURE Electrical stimulation was performed using a DISA stimulator unit (Type 14E 01) delivering square wave pulses of $50-100 \mu \mathrm{s}$ duration. The stimuli were applied through thin uninsulated steel needles, diameter $0.2 \mathrm{~mm}$, inserted intradermally about $2-3 \mathrm{~mm}$ apart within the innervation zone of the impaled fascicle (on the dorsum of the hand or the fingers in radial nerve recordings, or near the medial malleolus in saphenous nerve recordings). The ground electrode, $2 \mathrm{~cm}$ wide, wrapped in a wet flannel bag, was placed between the stimulating and recording sites.

In most experiments, the stimulus frequency varied between $0 \cdot 5 / \mathrm{s}$ and $5 / \mathrm{s}$. However, when A fibre responses were studied, stimulus frequencies up to $100 / \mathrm{s}$ were used.

Notes were made of how the neural responses correlated with the subjective sensations aroused by the stimuli, but no serious attempts were made to get a precise measure of the stimulus strength used. However, in a few experiments the stimulus currents were estimated and found to vary between 1-20 mA. The degree of polarization was tested at the stimulating site in the skin by changing the polarity of the stimulus and by studying the variations of the stimulus current and the changes in stimulus artefact in the skin. The outcome of these tests showed that the polarizing effects under the stimulus conditions used were of such small magnitude that they could 


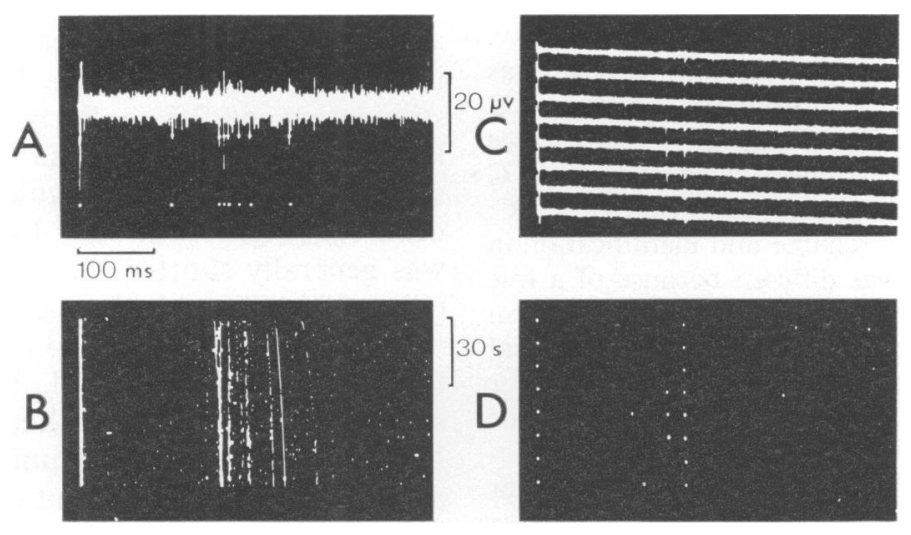

FIG. 2. Principles of the compact time presentation of electrically induced nerve responses. Distance between recording site in the radial nerve at the wrist and stimulating site in the dorsum of the hand $14 \mathrm{~cm}$. Due to the long time base only the C fibre responses are shown in Figs 2-6. Upward deflections represent positive signals at the intraneural electrode in Fig. $2 \mathrm{~A}, \mathrm{C}$ and Fig. $7 \mathrm{D}$. A: C fibre responses to a single painful electric shock applied to the receptive skin field (upper trace). The dots on the artefact and spikes mark the trigger level of the pulse former device. The dots at the bottom indicate the peaks of the uniform square wave pulses corresponding to the spikes in the neurogram. Time calibration refers to all records. B: Analysis during 75 seconds of many $C$ responses in the same recording position as in $\mathrm{A}$. Each shock, delivered at $1 / \mathrm{s}$, triggered the oscilloscope sweep, which continuously moved downwards. The $C$ fibre responses were easily discriminated from the random noise. C: $C$ unit responses to weak electric shocks delivered at $1 /$ s appearing all-or-nothing in the original neurogram. D: The same sequence as in $\mathrm{C}$ shown in dot display.

not have affected the interpretation of the results (Fig. 1).

SKIN TEMPERATURE MEASUREMENTS In some experiments the skin temperature was measured with a thermocouple applied to the skin near the stimulating electrodes. The temperature ranged from $28-32^{\circ} \mathrm{C}$ in four subjects and did not change more than $1^{\circ}$ during a single experiment. Thus, variations in temperature during the experiments were not likely to have affected the results to any considerable degree.

ANALYSING PROCEDURE The A fibre discharges were analysed at full recording bandwidth $(0 \cdot 2-10$ $\mathrm{kHz}(-3 \mathrm{~dB})$ ), whereas the $\mathrm{C}$ impulses had a lower frequency content and appeared more distinctly when the bandwidth was reduced to $0.5-2 \mathrm{kHz}$ $(-3 \mathrm{~dB})$. Generally, such a frequency cutting of the $\mathrm{C}$ signals was done before feeding the impulses into a pulse former device arranged to transform spikes exceeding any desired amplitude to uniform square wave pulses. The level of the device was set just outside that of the noise and was beam-brightened on the impulses (Fig. 2A). The peaks of the standardized potentials appeared as dots on the oscilloscope sweeps. By triggering on the stimulus artefact and adding a slowly falling voltage ramp function to the traces as many successive sweeps passed the screen, neural responses time-locked to the electric stimuli appeared as compact vertical lines or curves (Fig. 2B) whereas noise and background activity formed an irregular dotted pattern. A similar type of display has been used for instance by Wall (1960).

If the discriminator level was set too close to 
the noise, components tended to be hidden in the density of dots derived from the background activity. On the other hand, if the background density was reduced by raising the discriminator level some $\mathrm{C}$ elements were lost (see Fig. 5A and B). In some cases the dot display could be checked against single $C$ unit responses in the original neurogram (Fig. 2C, $D)$, but in other cases a reliable unit identification in the untreated record was difficult because of a low signal-to-noise ratio. However, due to the long term presentation, even small deflections in the original response could be identified as compact curves or lines even if occasional discharges were hidden in the noise.

It was occasionally possible to show that irregular dot patterns reflected activity in units with complex waveforms distorted in the signal treatment. Such recordings and sparse or irregular patterns like that shown in the middle of record $4 \mathrm{~B}$ were discarded from the material and only compact latency curves of the types shown in Fig. 4A were included in the study.

\section{RESULTS}

LATENCY CHANGES IN SINGLE C UNIT RESPONSES TO REPETITIVE ELECTRIC SKIN SHOCKS The identification of single $\mathrm{C}$ unit discharges in recordings from intact human skin nerves was discussed in a previous report (Torebjörk and Hallin, 1974). On repeated application of electrical stimuli, the latencies of individual unit discharges often changed considerably in a systematic way. Using a compact time presentation of the evoked discharges, these latency changes could be checked in detail. An example is shown in Fig. 3A, where successive responses of an afferent single $C$ unit recorded in the saphenous nerve initially appeared at a latency of about $260 \mathrm{~ms}$. The electric shocks were applied within the unitary innervation zone in hairy skin near the medial malleolus, $23 \mathrm{~cm}$ from the recording site just distal to the knee. (The receptive properties of this unit to natural stimuli have been described in detail by Torebjörk and Hallin, 1974.) The unit was recruited by constant electric shocks of moderate intensity which caused no discomfort to the subject. On stimulation at a frequency of $0 \cdot 5 / \mathrm{s}$ just above threshold for unit activation, the latency of the unitary response slightly increased, most markedly during the first few discharges. When raising the stimulation frequency to $1 / \mathrm{s}$, the latency increase was more pro- nounced and an interposed extra shock from the $\mathbb{\Phi}$ stimulator immediately caused an additional increment in latency (Fig. 3A, arrow). During $\stackrel{\text { ? }}{=}$ stimulation at $2 / \mathrm{s}$, a fairly rapid increase in 6 latency was observed, and soon the unit responded with marked irregularity and blockings $\stackrel{\overbrace{}}{S}$ occurred (Fig. 3A, middle; Fig. 3B). The latency

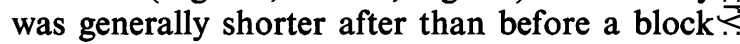
(Fig. 3B). The blocks initially came singly, $\overrightarrow{\vec{s}}$ whereas they appeared two or three at a time at the end of the test period. Further increase in $\frac{\mathrm{C}}{0}$ stimulus frequency resulted in pronounced $\frac{}{5}$ blocking, and at 10/s the unit responded on an $\frac{\widehat{Q}}{\Omega}$ average only three times out of 20 (Fig. 3C). The unit latency, in all, increased about $60 \mathrm{~ms}$ from the initial value when the testing started at $0 \cdot 5 / \mathrm{s}$ until it was interrupted at $10 / \mathrm{s}$ some $\vec{\omega}$ four and a half minutes later. When after a pause of about half a minute testing was resumed at $1 / \mathrm{s}$, the unitary latency was still increased in comparison with the beginning of the previous test period (Fig. 3A, bottom), indicating a slo recovery of conduction velocity after tetane stimulation.

Latency changes and blockings of this type were observed in many $\mathrm{C}$ units during repetitive electrical intradermal stimulation at compari tively low frequencies $(5 / \mathrm{s}-10 / \mathrm{s})$. On increasing $\overrightarrow{0}$ the stimulus intensity, the units reappeared if $t$ the responses, but as testing continued the latencies increased and blockings were observed again. The subjects spontaneously reported an increase in pain perception when the $\mathrm{C}$ units were $\frac{0}{8}$ recruited, and a successive decrease in pain during repetitive stimulation at constant intensity, when marked latency irregularities and blockings appeared in the $\mathrm{C}$ responses.

IDENTIFICATION OF SINGLE UNIT ACTIVITY IN ELECTRICALLY INDUCED MULTI C UNIT RESPONSES As pointed out earlier, it was difficult to differentiate between individual $\mathrm{C}$ units supplying the $\delta$ same skin area in responses to natural skin stimuli when the potentials had similar ampli- 의 tudes and interfered with each other (Torebjörk and Hallin, 1974). In such situations it was often possible to identify several individual $\mathrm{C}$ elements in the electrically induced responses using the display system described above. A typical recording is shown in Fig. 4. As the stimulus strength was increased from zero to a level experienced as 

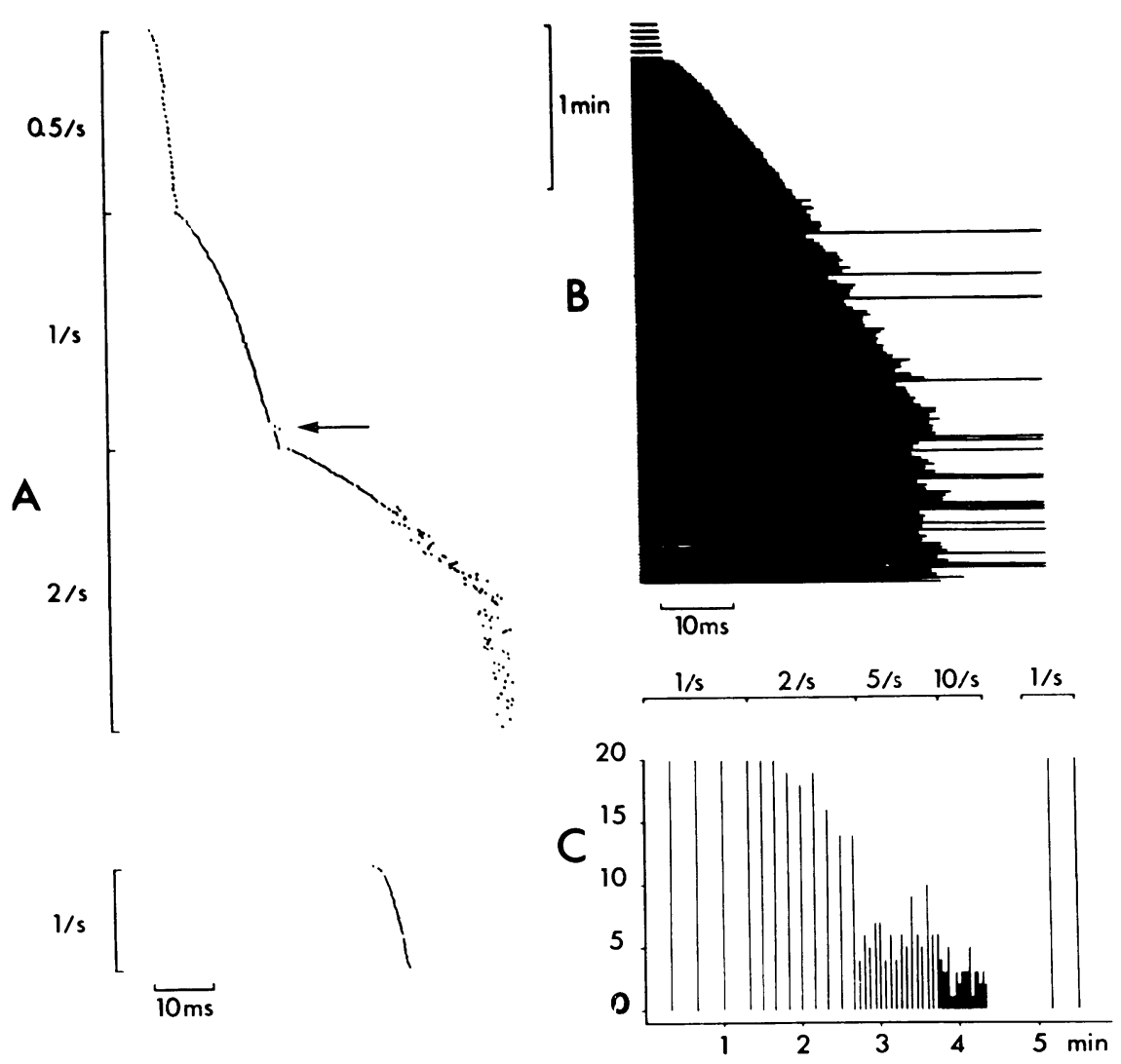

FIG. 3. Latency changes and blockings of an afferent $C$ unit triggered by electrical skin shocks of variable frequency. Unit recorded from left saphenous nerve $23 \mathrm{~cm}$ from the stimulating site near the medial malleolus. Skin temperature $28^{\circ} \mathrm{C}$. A : compact time display of the unitary responses which appeared with a latency of 260-265 ms when stimulating at $0 \cdot 5 / \mathrm{s}$. The first $250 \mathrm{~ms}$ after the stimulus artefact are omitted. Upon small increases in stimulus frequency the unit latency increased and at $2 / \mathrm{s}$ blockings appeared. After short periods of stimulation at $5 / \mathrm{s}$ and $10 / \mathrm{s}$ (not shown in the compact time display) the testing was interrupted for half a minute. After this pause the testing was resumed at $1 / s$. The arrow marks a transient latency increase due to an extra shock of the stimulator. B: detailed display of the end of the stimulus sequence at $1 / \mathrm{s}$ and the whole sequence of $2 / \mathrm{s}$. Each line indicates the latency of the unit response with the first $275 \mathrm{~ms}$ omitted. The long uniform lines mark unitary blockings. C: each vertical line indicates the number of centripetally conducted $C$ unit impulses in a sequence of 20 consecutive stimuli. The stimulus frequency is shown at the top. Note the pronounced degree of blocking at high stimulus frequencies.

weak pricking pain, three $\mathrm{C}$ elements were excited one by one, appearing at separate latencies. The three components exhibited individual differences in latency increase in responses to stimulation at $1 / \mathrm{s}$, the increase being most obvious during the first discharges for all elements (Fig. 4A). On decreasing the stimulus voltage, the elements disappeared in reverse order of recruitment.

These particular elements could be identified also among a larger population of $\mathrm{C}$ deflections as shown in Fig. 4B. After a prompt increase in stimulus intensity from a level experienced as pricking to a painful level (indicated by vertical 

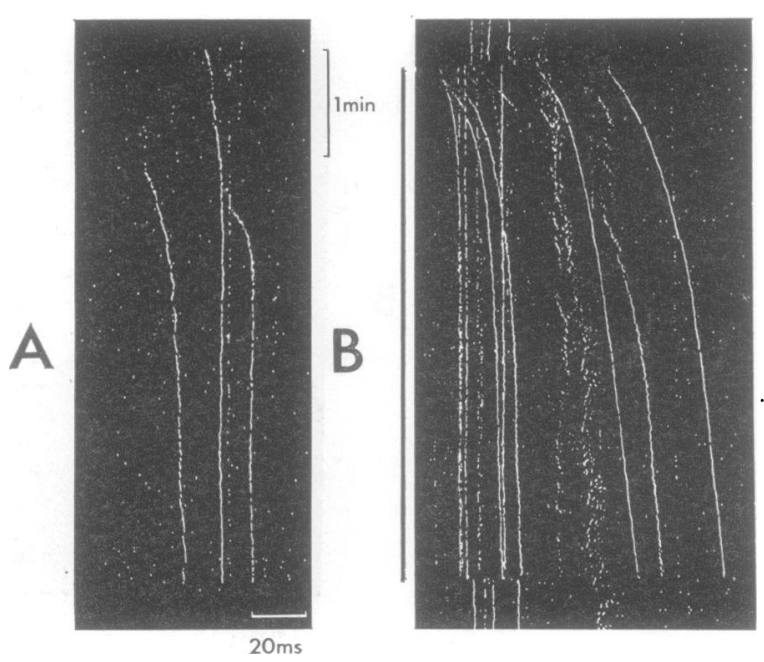

FIG. 4. Threshold and latency differences of individual $C$ elements in responses to electric skin shocks of varying intensity. Recording from the radial nerve at the wrist. Conduction distance $15 \mathrm{~cm}$. Skin temperature $32^{\circ} \mathrm{C}$. Figs 4-6 derive from the same experiment. Stimulus frefrequency $1 / \mathrm{s}$ in Fig. 4. The first $140 \mathrm{~ms}$ after the stimulus artefact are omitted in $\mathrm{A}$, and in $\mathrm{B}$ the first $175 \mathrm{~ms}$ are omitted. A: on slowly raising the shock intensity from zero to a level experienced as pricking, three $C$ elements with different latencies were recruited at different thresholds. B: on suddenly raising the stimulus strength from a low to a high intensity the latencies of the previously excited $C$ elements abruptly decreased. The newly recruited $C$ elements were easily recognized, since they exhibited latency increases during the period of constant, high intensity stimulation (indicated by bar).

bar in Fig. 4B) the latencies of the three previously active elements abruptly decreased, and a number of additional $\mathrm{C}$ components were recruited. Typically, the newly excited $\mathrm{C}$ elements showed pronounced latency increases which were most evident during the first minutes of repetitive stimulation and they appeared as curved lines in the compact display. In contrast, the previously active elements had a relatively constant latency for the stimulation frequency used and they appeared as nearly vertical lines. When the stimulus intensity was lowered to the previous level, the low-threshold elements reappeared at their former latencies, whereas the remainder of the $\mathrm{C}$ fibre population disappeared (Fig. 4B, bottom).
Further evidence for the unitary character of the elements in the $\mathrm{C}$ response was obtained from the fact that they exhibited individual differences in ability to follow stimulation at higher frequencies. The results of such an experiment are shown in Fig. 5A. Initially the test frequency was $2 / \mathrm{s}$ (top), thereafter it was temporarily raised to $3 / \mathrm{s}$ (middle) and then again lowered to $2 / \mathrm{s}$ (bottom). All components of the $\mathrm{C}$ response increased in latency during stimulation at the higher frequency, and one of them (arrow) appeared with marked irregularity and finally blocked. On decreasing the stimulation frequency there were also individual differences in recovery of the different components. 


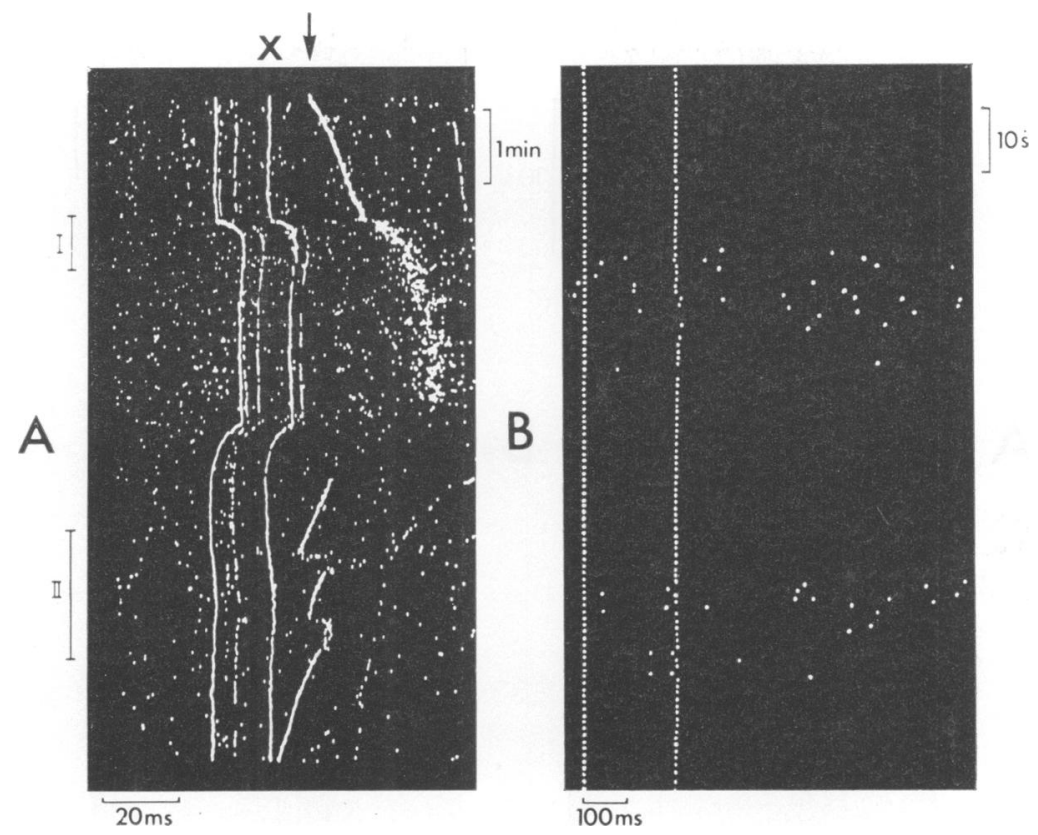

FIG. 5. Latency changes in a population of $C$ elements during electrical stimulation of variable frequency. A: electric shocks were delivered at $2 / s$ (top and bottom) and at $3 / s$ (upper middle). $\times$ and arrow mark different $C$ elements, $170 \mathrm{~ms}$ after the stimulus artefact are omitted. B: the sequence marked II in A shown with long time base. The left dotted row marks the stimulus initiation. The level of the pulse former device was adjusted so that impulses in a large, 'spontaneously' firing unit marked with an arrow in Fig. 4 A appeared in the dotted display. During the 'spontaneous' activity the latency of the electrically induced unitary responses increased and blockings occurred. After the outbursts the unit reappeared with successively shorter latencies in the evoked responses (Fig. 4A, bottom).

LATENCY CHANGES OF DUALLY EXCITED C ELEMENTS In some cases additional firing in a particular element within the $\mathrm{C}$ population was elicited by stimuli other than the electric test shocks. A dual excitation of a $\mathrm{C}$ element resulted in changes in the corresponding compact latency curve. Such a dually activated C component is shown in Fig. 5A (arrow). This element which was clearly identified as a single $C$ unit in the original neurogram sometimes exhibited short outbursts of impulses at an instantaneous frequency up to 20/s (Fig. 5A, bottom; Fig. 5B). It could not be determined whether the discharges occurred 'spontaneously' or if they were induced by some external stimulus. Nevertheless, the latency curve changed markedly during the episodes of dual activation. During these outbursts the latencies of the electrically triggered responses increased. When the bursts were vigorous the element became inexcitable to electrical stimulation and blockings appeared. However, discharges still occurred in the fibre indicating that the axon was excitable by other stimuli (Fig. 5B). Following the transient decrease in excitability after an outburst, the latency of the unitary response successively diminished in a way similar to that upon recovery after high frequency electrical stimulation (Fig. 5A, middle).

BIMODAL OR POLYMODAL LATENCY DISTRIBUTIONS Many of the $\mathrm{C}$ units exhibited abrupt latency 
changes different from the exponential latency variations previously described. Such latency 'leaps' could sometimes appear even after a few responses to constant electrical stimulation. During prolonged stimulation the latencies could be bimodally distributed, the responses alternating between shorter or longer latencies, and finally being visible only at the longer latencies. Such stepwise increases in latency amounted to 3-10 ms.

Several of the elements had a relatively stable latency during constant low frequency stimulation but showed a bimodal latency distribution when the test frequency was increased. The element marked $\times$ in Fig. 5A and Fig. 6A was a typical example. On raising the stimulation frequency from $2 / \mathrm{s}$ to $3 / \mathrm{s}$ there was initially an increase in latency, but after about 20 seconds, discharges of this unit (as identified by amplitude $\stackrel{2}{\rightarrow}$ and shape in the original neurogram) appeared either around 225 or $229 \mathrm{~ms}$ after the stimulus artefact. Occasional blockings occurred. The bimodal latency distribution remained during the rest of the stimulation sequence of $3 / \mathrm{s}$ but could not be observed when the stimulus frequency was lowered again.

The C elements regularly appeared at successively longer latencies on slowly decreasing the stimulus strength, probably as a consequence of spread of the stimulus to more distal segments of the fibres. Such continuous increases in latency were generally small (only a few ms). However, 今 some $\mathrm{C}$ units exhibited abrupt latency increases in one or more steps of the order of 3-10 ms on successively decreasing the stimulus, and steps of similar magnitudes in reverse direction were ob- 


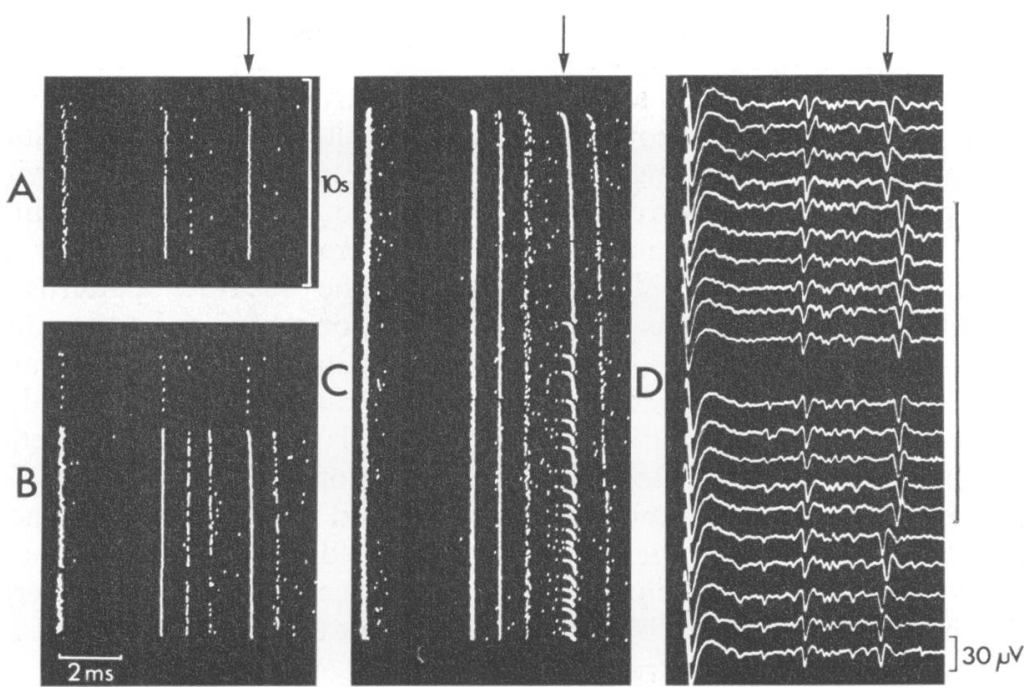

FIG. 7. Compact time presentation of $A$ fibre responses in the radial nerve during different stimulus frequencies. Distance of conduction $10.5 \mathrm{~cm}$. Component marked with an arrow was identified as a single unit. Triggering points were identical in all tests, although late parts of the stimulus artefacts appear with irregularity to the left in $\mathrm{A}, \mathrm{B}$, and $\mathrm{C}$. The test periods were separated from each other by pauses of 20-30 seconds. About 10 unit responses were omitted in the middle of the $\mathrm{D}$ sequence. $\mathrm{A}$ : rapid increase of stimulus frequency from $1 / s$ to $5 / s$. B: stimulus frequency $2 / s$ (top) and 20/s (lower part). C: stimulus frequency set to 50/s. Initially, the unit component marked with an arrow was excited by each shock, but after some 10 seconds blockings appeared. D: the unit indicated with an arrow exhibited an abrupt increase in latency on slightly reducing the stimulus strength (top) and changed back to its initial position in the response when successively resuming testing with the previous shock intensity (bottom). The bar marks the sequence of low intensity stimulation.

served on progressive increase of the stimulus strength. Such step-wise latency changes as illustrated in Fig. 6B were reproducible and characteristic for individual elements.

RESPONSES IN A FIBRES TO ELECTRICAL STIMULI OF VARYING FREQUENCY In eight experiments, where individual A fibre units were identified in the neurogram, the latency changes of A fibre responses were studied on varying the stimulus frequency. In the experiment illustrated in Fig. 7 several A components can be seen. Like C elements, A components tended to exhibit increased latencies after an increase in stimulus frequency. The latency prolongation was best seen during the first few discharges of activation (Fig. 7A-C, top) before the components stabilized at their longer latencies. Changes in stimulus frequency from $0.5 / \mathrm{s}$ up to $50 / \mathrm{s}$ were followed by very small changes in latency, often less than $0.3 \mathrm{~ms}$ for components in the early part of the A response (conduction velocity $70-30 \mathrm{~m} / \mathrm{s}$, distance of conduction $8-11 \mathrm{~cm}$ ). Blockings were generally not seen.

Occasionally responses in A components of long latency (conduction velocity $30-15 \mathrm{~m} / \mathrm{s}$ ) were studied. The unit marked with an arrow in Fig. 7 had a conduction velocity of about $17 \mathrm{~m} / \mathrm{s}$. After increases in stimulus frequency, the latency of this unit increased somewhat more than for short latency A components, but the increase did not exceed $0.5 \mathrm{~ms}$ (Fig. 7A, B). The unit re- 
sponded to each stimulus applied at rates up to $30 / \mathrm{s}$. When the stimulus rate was raised to $50 / \mathrm{s}$ the unit was initially regularly evoked at each shock, but already after about 10 seconds of stimulation occasional blockings appeared (Fig. 7C). After each rest period the unit recurred with shorter latency and then the latency increased until it blocked once more. With continuing stimulation the unit blocked more frequently (Fig. 7C, bottom).

By contrast with $\mathrm{C}$ elements, components in the early part of the A response did not exhibit abrupt step-wise latency changes. However, units with calculated conduction velocities ranging from $15-30 \mathrm{~m} / \mathrm{s}$ sometimes showed a bimodal latency distribution, reminiscent of $\mathrm{C}$ elements (Fig. 7D), but the time interval between the different latencies was relatively short, seldom exceeding $0.5 \mathrm{~ms}$.

\section{DISCUSSION}

IDENTIFICATION OF SINGLE UNIT ACTIVITY IN THE COMPACT DISPLAY In earlier reports $A$ and C fibre responses to electric skin stimulation were visualized with a computer of average transients (Hallin and Torebjörk, 1970a; 1973). However, individual peaks in the computer records usually represented activity in many nerve fibres, and single unit responses were difficult to study using this procedure. As pointed out by Paintal (1965), the compound action potential may give an erroneous impression about conduction block in different fibre groups. This is due to the fact that an increase in conduction time, particularly in thin fibres on, for instance, cooling, causes a pronounced dispersion of the long latency waves that makes them indistinguishable from the noise level of the tracing. This disadvantage was overcome by using the compact time presentation of the induced nerve responses which permitted a detailed study of $\mathrm{A}$ and $\mathrm{C}$ components of the induced activity when the signal-to-noise ratio was also relatively low. The identification of single elements was facilitated when the conduction distance was long due to temporal dispersion of responses in fibres with different conduction velocities. In particular, identification of single $\mathrm{C}$ unit deflections was often possible even if several $\mathrm{C}$ fibres responded to the stimuli.
The following findings suggested that indi-⿱亠⿴囗十 vidual long latency curves in several cases represented activity in single $\mathrm{C}$ units. The elements $\stackrel{(\mathcal{C}}{=}$ were recruited at individual excitation thresholds with different latencies. On varying the test conditions the latencies changed in different waysoิ which were characteristic for individual ele-⿳亠丷厂 ments. The separate patterns of successive,. irregular, or step-wise latency changes or block- $\overrightarrow{\vec{F}}$ ings facilitated the identification of single elements during long-term analysis even if the compact latency curves sometimes interfered $\overline{\bar{c}}$ with each other. Finally, some of the C elements $\widetilde{\Phi}$ represented in the compact latency display could be identified as single units in the original neurogram by the characteristics described previously? (Torebjörk and Hallin, 1974).

EFFECTS OF REPEATED STIMULATION During a period following tetanization of a nerve the excitability and conduction velocity of the nerwe fibres are subnormal (Gasser, 1935). On stimul $\overline{\mathbf{q}}$ tion with electric shocks at high frequency, the $\mathrm{f}$ is an exponential decline of conduction veloci范 of both myelinated (Tasaki, 1953) and no myelinated fibres (Franz and Iggo, 1968). bi agreement with the above results, our studie $\infty$ showed a progressive frequency dependent i⿺辶⿸广巳 $\overrightarrow{0}$ crease in latency of both $A$ and especially components to repetitive electrical stimulation until the latencies successively stabilized after a number of impulses. The very pronounced after-o effects in C fibres are probably due to large ionic $\stackrel{2}{\circ}$ changes occurring during repetitive activity in $\triangle$ small fibres with a large surface/volume ratio $\overline{\mathrm{o}}$ (Ritchie and Straub, 1957).

On intradermal stimulation a slowing of conduction velocity and a decrease in excitability of $\mathrm{C}$ fibres was demonstrated even at frequencies as low as $0.5 / \mathrm{s}$. These effects were possibly due to the influence of the skin temperature $\left(28-32^{\circ} \mathrm{C}\right) 3$ on nerve conduction (Franz and Iggo, 1968). In addition, it seems reasonable to assume that the stimulated peripheral nerve segments were very $ᄋ$ thin, thus being much affected by repetitive activity. In this context it should be recalled that C fibre receptors easily 'fatigue' (Iggo, 1959, 1960; Hallin and Torebjörk, 1970b; Bessou et ${ }^{\circ}$ al., 1971) - that is, respond less vigorously to repetition of a mechanical stimulus. It has been $\omega$ suggested that this depression of sensitivity also 
may be due to ionic changes in fine receptor terminals after a period of repeated excitation (Iggo, 1972). A failure to respond to submaximal repetitive electrical stimulation in the skin did not indicate incapacity of impulse conduction in the axon. On the contrary, an increase in stimulus intensity regularly recruited the $\mathrm{C}$ elements again. Furthermore, the unit illustrated in Fig. 5B was active in spite of being inexcitable to the electric shocks. The discharge frequency could be comparatively high, provided the stimulus was intense. For instance, the unit shown in Fig. 3 discharged at an instantaneous frequency up to $50 / \mathrm{s}$ for short periods in response to intense stimuli such as painful heating of the skin (Torebjörk and Hallin, 1974).

IDENTIFICATION OF DUALLY EXCITED C UNITS IN THE COMPACT LATENCY DISPLAY The latency changes of the $\mathrm{C}$ responses were most pronounced in the first responses on varying the stimulus frequency. Momentary changes in firing frequency such as an extra impulse or a single block were therefore easily recognized as a relatively large latency increase or decrease in the latency curve (Fig. 3A, B). In some cases, a particular unit within the multiunit $\mathrm{C}$ population exhibited increased firing due to activation other than the electric shocks. Such dually excited C units could be reliably identified in the centripetally conducted $\mathrm{C}$ response by latency changes or blockings associated with a period of increased activity. This finding opens up the possibility for determining which elements within a population of electrically excited $\mathrm{C}$ units respond also to a particular natural stimulus within the receptive field. It is also suggested that in this way afferent and sympathetic $\mathrm{C}$ unit activity could be differentiated in the centripetally conducted $\mathrm{C}$ response.

STEP-WISE LATENCY CHANGES INDICATING DIFFERENT ROUTES OF IMPULSE PROPAGATION Some of the unitary A elements with slow conduction velocities $(30-10 \mathrm{~m} / \mathrm{s})$ and many of the $C$ units exhibited stepwise intervals in latency in responses to intradermal stimulation. This was possibly due to spread of the electrical stimulus from one nerve twig or segment to another on varying the shock intensity. In situations when abrupt latency changes were found at constant testing or after small increments in stimulus frequency, it seems reasonable to assume that some peripheral part of the nerve fibre became inexcitable to the stimulation due to influence of previous activity and that impulse conduction then occurred through a different route. Abrupt unit latency changes were also elicited by warming or cooling the receptive field during repetitive electrical stimulation of constant intensity (unpublished observations) which strongly suggested that the tendency of units to exhibit a polymodal latency distribution was associated with events in peripheral nerve structures. The findings agreed with the anatomical fact that both $\mathrm{A}$ and $\mathrm{C}$ fibre axons supplying the skin run irregular courses and dichotomize at the periphery (Miller et al., 1960).

CLINICAL ASPECTS Using conventional clinical macroelectrode techniques of recording from outside a nerve (Dawson and Scott, 1949) and superimposing or averaging many responses (Gilliatt and Sears, 1958; Buchthal and Rosenfalck, 1966) activity in large and small sized myelinated nerve fibres was often detected (Buchthal and Rosenfalck, 1966), but activity in unmyelinated nerve fibres was occasionally discriminated only when thousands of responses to intense painful electrical stimuli were averaged by computers (Buchthal et al., 1974). By contrast, the microelectrode technique of recording from inside intact nerve fascicles often allows analysis of impulses from both myelinated and unmyelinated fibres (Hallin and Torebjörk, 1970a, 1973). With the compact display described above the discrimination of individual elements was considerably improved so that detailed and momentary changes in populations of $\mathrm{A}$ and $\mathrm{C}$ fibres responding to the test shocks could be followed from stimulus to stimulus in successful recordings. The microelectrode explorations are not very painful for the subjects and seem to cause no enduring symptoms. It is suggested that the technique can be used not only to study conduction velocities in normal and diseased nerves but also to follow changes in neural activity induced by blocking manoeuvres (Torebjörk and Hallin, 1973) and to investigate the effects of topical agents influencing the neural activity of the skin during normal and pathological conditions. Since the subjects are alert 
during the recordings, the neural activity can always be correlated with perception.

Obviously, the measurements of conduction velocity in nerve fibres on stimulating in the skin involves many sources of errors (Hallin and Torebjörk, 1973). One error is the influence of repeated excitation on conduction velocity in thin fibres, as strikingly demonstrated in Fig. 3. The latency increase of this unit, about $60 \mathrm{~ms}$, during testing at different frequencies for 4.5 minutes corresponded to a decrease in conduction velocity from 0.88 to $0.72 \mathrm{~m} / \mathrm{s}$. Even larger changes in conduction velocity were sometimes observed after tetanic stimulation.

In previous experiments, where the averaged nerve response was directly checked against the sensations aroused by electrical stimulation in the skin, a marked decrease in the experience of pain was reported during the first minute of constant, high intensity 5/s stimulation. The decrease in pain perception was accompanied by a reduction of the $\mathrm{C}$ fibre response (Torebjörk and Hallin, 1973). Similarly, a time correlation was also noted in this study between reports of reduced pain perception and blockings of the $\mathrm{C}$ response to repeated stimulation. Central mechanisms are certainly involved in the habituation to the stimuli, but the results of these tests suggest that excitation failure in peripheral thin nerve fibres also might be responsible for part of the decrease in pain perception during repetitive electrical intradermal stimulation. The clinical significance of this peripheral mechanism remains to be studied.

\section{REFERENCES}

Bessou, P., Burgess, P. R., Perl, E. R., and Taylor, C. B. (1971). Dynamic properties of mechanoreceptors with unmyelinated (C) fibers. Journal of Neurophysiology, 34, 116-131.

Buchthal, F., and Rosenfalck, A. (1966). Evoked action potentials and conduction velocity in human sensory nerves. Brain Research, 3, 1-122.

Buchthal, F., Rosenfalck, A., and Behse, F. (1974). Sensory potentials of normal and diseased nerves. In Peripheral Neuropathy. Edited by P. Dyck, P. K. Thomas, and E. H. Lambert. W. B. Saunders: Philadelphia, London, Toronto. (In press.)

Dawson, G. D., and Scott, J. W. (1949). The recording of nerve action potentials through skin in man. Journal of Neurology, Neurosurgery, and Psychiatry, 12, 259-267.

Franz, D. N., and Iggo, A. (1968). Conduction failure in myelinated and non-myelinated axons at low temperatures. Journal of Physiology, 199, 319-345.

Gasser, H. S. (1935). Changes in nerve-potentials produced $T$ by rapidly repeated stimuli and their relation to the

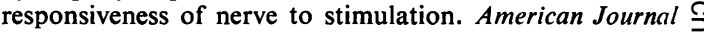
of Physiology, 111, 35-50.

Gilliatt, R. W., and Sears, T. A. (1958). Sensory nerve acticn potentials in patients with peripheral nerve lesions. Journal of Neurology, Neurosurgery, and Psychiatry, 21, 109-118.

Hagbarth, K.-E., Hongell, A., Hallin, R. G., and Torebjörk, H. E. (1970). Afferent impulses in median nerve fascicles evoked by tactile stimuli of the human hand. Brain Research, 24, 423-442.

Hallin, R. G., and Torebjörk, H. E. (1970a). C-fibre components in electrically evoked compound potentials recorded from human median nerve fascicles in situ. Acta Societatis Medicorum Upsaliensis, 75, 77-80.

Hallin, R. G., and Torebjörk, H. E. (1970b). Afferent and $\vec{O}$ efferent $\mathrm{C}$ units recorded from human skin nerves in situ. Acta Societatis Medicorum Upsaliensis, 75, 277-281.

Hallin, R. G., and Torebjörk, H. E. (1973). Electrically induced $A$ and $C$ fibre responses in intact human skin nerves. Experimental Brain Research, 16, 309-320.

Iggo, A. (1959). A single unit analysis of cutaneous receptors with C afferent fibres. In Pain and Itch, pp. 41-59. Edited by G. E. W. Wolstenholme and M. O'Connor. Cibo Foundation Study Group No. 1. Churchill: London.

Iggo, A. (1960). Cutaneous mechanoreceptors with affere $\$$ C fibres. Journal of Physiology, 152, 337-353.

Iggo, A. (1972). The case for 'pain' receptors. In Pain po 60-67. Edited by R. Janzen, W. D. Keidel, A. Herz, Steichele, J. P. Payne, and R. A. P. Burt. Georg Thiemen Stuttgart; Churchill Livingstone: London.

Miller, M. R., Ralston, H. J., III, and Kasahara, M. (1960 The pattern of cutaneous innervation of the human hanळ; $v$ foot and breast. In Cutaneous Innervation, pp. 1-4 + Advances in Biology of Skin. Vol. 1. Edited by W. Montagna. Pergamon Press: Oxford.

Paintal, A. S. (1965). Block of conduction in mammalian myelinated nerve fibres by low temperatures. Journal of Physiology, 180, 1-19.

Ritchie, J. M., and Straub, R. W. (1957). The hyperpolarization which follows activity in mammalian non-medullated fibres. Journal of Physiology, 136, 80-97.

Tasaki, I. (1953). Nervous Transmission, pp. 85-88. Charles C. Thomas: Springfield, Ill.

Torebjörk, H. E., and Hallin, R. G. (1970). C-fibre units recorded from human sensory nerve fascicles in situ. Acta Societatis Medicorum Upsaliensis, 75, 81-84.

Torebjörk, H. E., and Hallin, R. G. (1973). Perceptual changes accompanying controlled preferential blocking of $\mathrm{A}$ and $\mathrm{C}$ fibre responses in intact human skin nerves. Experimental Brain Research, 16, 321-332.

Torebjörk, H. E., and Hallin, R. G. (1974). Identification of afferent $C$ units in intact human skin nerves. Brain Research, 67, 387-403.

Vallbo, A. B., and Hagbarth, K.-E. (1968). Activity from skin mechanoreceptors recorded percutaneously in awake human subjects. Experimental Neurology, 21, 270-289.

Wall, P. D. (1960). Cord cells responding to touch, damage, and temperature of skin. Journal o Neurophysiology, 23, N 197-210. 